\title{
Clinical Benefit of American College of Chest Physicians Versus European Society of Cardiology Guidelines for Stroke Prophylaxis in Atrial Fibrillation
}

\author{
Ambar A. Andrade, $\mathrm{MD}^{1,2}$ and Brian F. Gage, MD, MSc ${ }^{7}$ \\ 'Washington University in St. Louis, St. Louis, MO, USA; ${ }^{2}$ Texas Heart Institute, Houston, TX, USA.
}

J Gen Intern Med 30(10):1405

DOI: $10.1007 / \mathrm{s} 11606-015-3378-3$

() Society of General Internal Medicine 2015

$\mathrm{W}$ e thank Larsen et al. for their interest in our work and for an opportunity to clarify our research. We found that the risks outweighed the benefits of expanding warfarin use to patients 65-74 years of age with a CHADS 2 score of 0 . We came to this conclusion based on an examination of the risks and benefits of prescribing warfarin in a Medicare population who had none of the $\mathrm{CHADS}_{2}$ risk factors for stroke (congestive heart failure, hypertension, age $>75$ years, diabetes mellitus, or a prior stroke or transient ischemic attack).

Even when warfarin is carefully monitored in randomized trials of highly selected participants, it doubles the risk of major hemorrhage. ${ }^{1}$ Outside of trials, hemorrhage rates are higher, averaging 4 major bleeds per 100 patient-years with warfarin use in Medicare-age patients. ${ }^{2}$ We found that prescribing warfarin to this low-risk population nearly tripled the rate of major hemorrhage (hazard ratio 2.9; $95 \%$ CI 1.5-5.4). As compared to warfarin, novel anticoagulants have lower risks of intracranial hemorrhage but risks of extracranial hemorrhage that are equivalent or higher. ${ }^{3}$ Whether the benefits of novel anticoagulants outweigh their risks in patients with a $\mathrm{CHADS}_{2}$ score of 0 is unknown, as low-risk patients were excluded from trials of novel anticoagulants.

The benefits of anticoagulants in clinical practice are lower than in randomized trials. In our cohort of 65-74-year-old patients with a $\mathrm{CHADS}_{2}$ score of 0 , the stroke equivalents per 100 patient-years were 2.6 with warfarin and 2.9 without warfarin; the difference between these two strategies was not significant. Although our dataset was from the 1990s, over the past two decades, stroke rates have declined, which means that the benefit of anticoagulant therapy also has declined. For example, a recent population-wide study found that the stroke rate for this low-risk population was less than $0.9 \%$ per 100 patients-years ${ }^{4}$ - below the $1 \%$ to $2 \%$ stroke rate that most patients require before they are willing to take warfarin chronically. ${ }^{5}$

In summary, the risks of expanding warfarin use to patients 65-74 years of age with a CHADS 2 score of 0 outweighed the benefits in our real-world population. We agree that our data had limitations and that further study of risks and benefits is needed. We also agree that the risks of dual-antithrombotic therapy often outweigh the benefits among patients with atrial fibrillation. Therefore, we prescribe aspirin (without additional antithrombotic therapy) in these low-risk patients. One benefit of aspirin is its cardioprotective effect; another is that it is costeffective in this population, while anticoagulants are not. ${ }^{6}$

Conflict of Interest: The authors declare that they do not have a conflict of interest.

Corresponding Author: Brian F. Gage, MD, MSc; Washington University in St. Louis, 660 S. Euclid Ave, Campus Box 8005, St. Louis, MO 63110, USA (e-mail: bgage@dom.wustl.edu).

\section{REFERENCES}

1. Hart RG, Pearce LA, Aguilar MI. Meta-analysis: antithrombotic therapy to prevent stroke in patients who have nonvalvular atrial fibrillation. Ann Intern Med. 2007;146(12):857-67.

2. Hylek EM, Evans-Molina C, Shea C, Henault LE, Regan S. Major hemorrhage and tolerability of warfarin in the first year of therapy among elderly patients with atrial fibrillation. Circulation. 2007;115(21):2689-96.

3. Hernandez I, Baik SH, Pinera A, Zhang Y. Risk of bleeding with dabigatran in atrial fibrillation. JAMA Intern Med. 2015;175(1):18-24. doi:10.1001/ jamainternmed.2014.5398.

4. Friberg L, Skeppholm M, Terent A. Benefit of anticoagulation unlikely in patients with atrial fibrillation and a CHA2DS2-VASc score of 1. J Am Coll Cardiol. 2015;65(3):225-32. doi:10.1016/j.jacc.2014.10.052.

5. Man-Son-Hing M, Gage BF, Montgomery AA, et al. Preference-based antithrombotic therapy in atrial fibrillation: implications for clinical decision making. Med Decis Making. 2005;25(5):548-59. doi:10.1177/ 0272989X05280558.

6. Shah SV, Gage BF. Cost-effectiveness of dabigatran for stroke prophylaxis in atrial fibrillation. Circulation. 2011;123(22):2562-70. doi:10.1161/ CIRCULATIONAHA.110.985655. 